\title{
Partaker Agency: Entanglement of agencies in artworks by Bekirovic and Abramović.
}

\author{
Saskia Isabella, Maria Korsten \\ ArtEZ University of the Arts, \\ Amsterdam, The Netherlands \\ saskiakorsten@hotmail.com \\ s.korsten@artez.nl
}

\begin{abstract}
In this paper I enquire 'partaker agency' in artworks by Semâ Bekirovic and Marina Abramović. Partaker agency is a concept which describes the agencies at work in collaborations between the various entities of an artwork in its coming to 'life.' Partaker agency is already at work in the very first conception of the artwork, during the process of making, and until and beyond the interaction with the audience. This whole process is, following Karen Barad (2003), how matter starts to 'matter.'
\end{abstract}

Partaker Agency. Life-Art-Life. Process. Event. Non/Human Collaboration.

We do not obtain knowledge by standing outside of the world; we know because "we" are part of the world.

- Karen Barad

\section{INTRODUCTION}

In her 'The Radiance of Sensible Heat 02' (2016), artist Semâ Bekirovic allows us a glance over sculptures in the dark only lit by the touch of a warm hand caressing the sculpture captured by a heatsensitive camera. The sculpture is brought to life by the hands and radiates its presence. Human, nonhuman and human-like entities work together in the works of Bekirovic. In this paper I will enquire the role of what I will coin partaker agency in the works by Bekirovic and, in comparison, with Marina Abramović's works. Partaker agency is to be understood as the agency at work in collaborations between the various entities within an artwork in its coming to 'life.' Partaker agency is already at work in the very first conception of the artwork, during the process of making, and until and beyond the interaction with the audience. This whole process is, following Karen Barad, how matter starts to 'matter.' Texts by Susanne Langer and Alexander Dorner from the 1950's in which they argue for processual art and comparing art to life, will be used to arrive at the timely notions on interactions between human and non-human agents following texts by Donna Haraway, Barad and Brian Massumi. They question the hard lines between subjectivity and objectivity, or any dualistic thinking. Massumi for instance states that:

$$
\begin{aligned}
& \text { [...] when we see an object's shape we are not } \\
& \text { seeing around to the other side; what we are } \\
& \text { seeing, in a real way, is our capacity to see the } \\
& \text { other side }(2007,73) \text {. }
\end{aligned}
$$

This can be read as a collaboration between object and viewer to form a live-like percept. This idea quite literally relates to Bekirovic's 'The Radiance of Sensible Heat 02.' Her works show great scientific interest but are nevertheless a lot more subjective and less goal-oriented (Stern). She asserts to be actually showing the unwillingness of the world to remain within objective parameters. This is connected to Haraway's statement that:

[...] there is no unmediated photograph or passive camera obscura in scientific accounts of bodies and machines; there are only highly specific visual possibilities, each with a wonderfully detailed, active, partial way of organizing worlds (10).

Bekirovic accordingly shows in her work that viewing is not an act of a fixed eye only. It is about entities co-creating an event, entangling the viewer and the object in a form of partaker agency. 


\section{LIFE ART_ART LIFE}
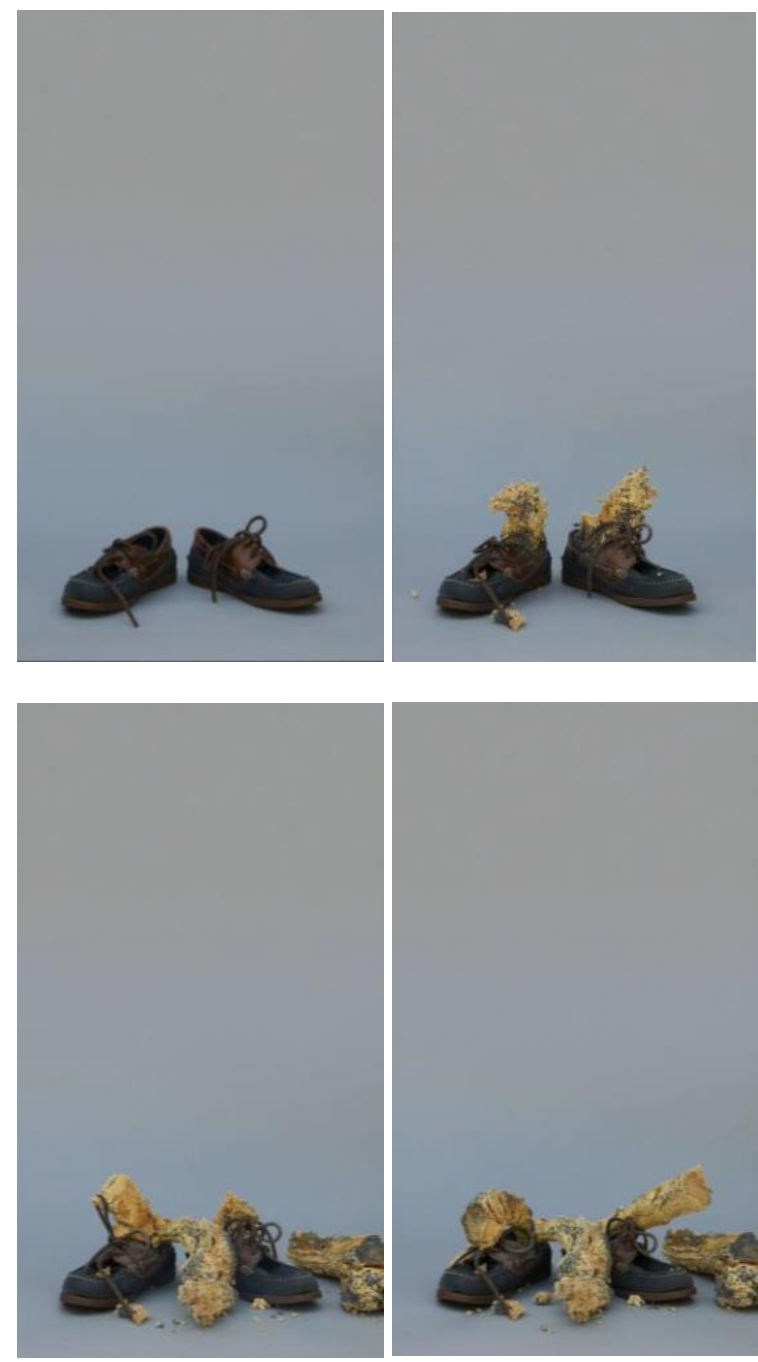

Figures 1a-d: Stills 'Shoes’ by Semâ Bekirovic, 2015.

In Semâ Bekirovic's video work 'Shoes,' two shoes are ready for departure yet lack a moving force. They look new, uninhabited. The shoelaces are gracefully tied. Then suddenly, accompanied by little whiffs of smoke that let little flakes of something flutter up, some kind of matter is rising. It is growing vertically out of the shoes where normally a human ankle would be. Little flames cause a chemical reaction which escalates a column of brittle material out of the shoes. It crumbles at the sides, slowly tips over, then bigger chunks come off until it entirely breaks off at the base. New material is formed to produce yet another pair of substitute ankles until the chemical reaction wears out. The shoes are left with the residue of material on the ground beside them and with some left over matter in them that has stopped growing, which hoovers in mid-air, heels over, right before it breaks off. The shoes will not depart.
In her book 'Feeling and Form' Susanne Langer relates art to life. When a mouse runs over the floor, it covers a path lying on the floor; so, where motion takes place, it defines a lasting conceptual line even when it leaves no trace. It is the abstract principle of direction that a linear design and a real motion both embody. We let them stand proxy for each other all the time. Langer states that this function is non-discursively exhibited and perceived long before it is acknowledged in a scientific device. The matter growing in Bekirovic's shoes defines a vertical path upwards, resembling human legs. The vital principle of growth gives the event a life-like experience. It resembles growing organic 'life' though it is in fact accumulating 'dead' matter. The empty space at the upper part of the vertically positioned video screen allows for a much larger entity being grown out of the shoes. Langer gives a concrete definition of how she sees growth and life:

\begin{abstract}
When growth is more vigorous than decay the living form grows larger; when they are balanced it is self-perpetuating; when decay occurs faster than growth the organism is decadent. At a certain point the metabolic process stops all at once, and the life is finished (65).
\end{abstract}

This is exactly what seems to be visualized in the work 'Shoes.' Langer pointed out that we let designmotion and life-motion stand proxy for each other in such a way that we come to perceive a drawn spiral as spiralling. That is just what might happen in Bekirovic's work when she simulates growth. Massumi takes Langer's notions away from the specific art theory to perception theory in general by explaining how the backedness of things is implied in simply inferring the back of an object by looking at it from one position. He states that:

[...] The potential we see in the object is a way our body has of being able to relate to the part of the world it happens to find itself in at this particular life's moment $(2007,73)$.

\section{And Alexander Dorner described that:}

\section{[...] process is making its way into that which is known and the idea of operations into our account of how we know (9).}

In Dorner's account an "event" proceeds from a total process. "Fact," to him is that which is done. Event and fact enter together as inceptions of new events and new things to be done.

This procedure is also how I should like to approach the work of art: as an event proceeding from a continual process of entanglement of agencies. 


\section{PARTAKER AGENCY}

John Dewey writes about the idea of a person as an individual in the introduction of Dorner's book. He sketches the lineage from the individual as a fixed element in a given larger whole towards the idea of "The Individual" as fixed in himself. Dewey sums up Dorner's new outtake on this position as follows:

Against these fixations, Dr. Dorner points to the personal individual as partaker in the "general process of life" and as a "special contributor to it." This union of partaker and contributor describes the enduring work of the artist (10).

In the following section I will compare works by Semâ Bekirovic to works by Marina Abramović in order to discern different positions towards my notion of partaker agency.

The potential that I recognize as life-potential in the work 'Shoes' presents the human viewer with nonhuman agency. It is by simulating a form of 'lifepotential' that it can make itself felt as agency.

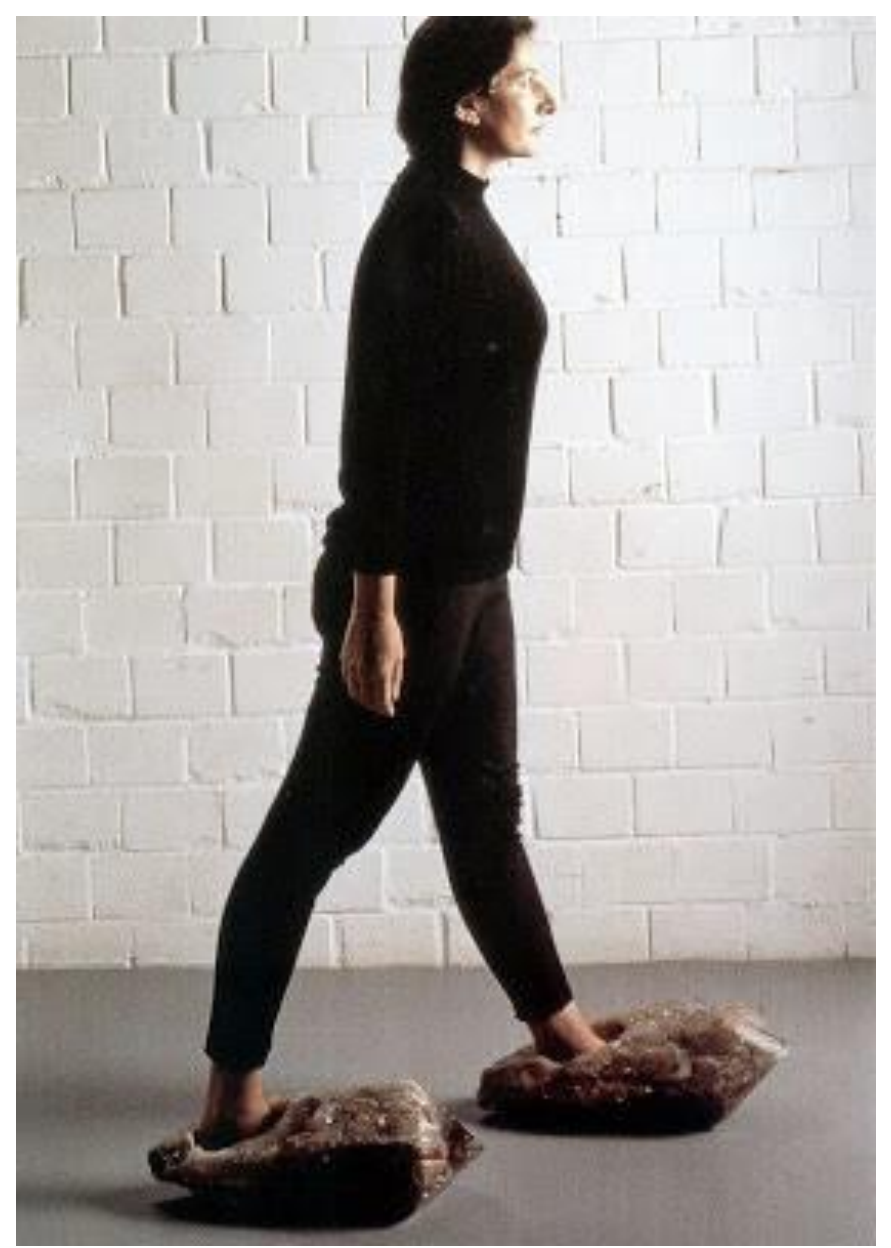

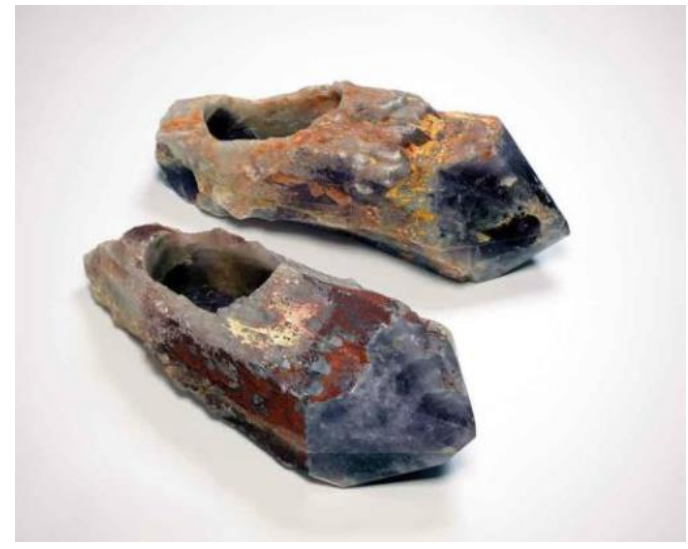

Figures 2a and b: 'Shoes for Departure' by Marina Abramović, 1991.

'Shoes' brings to mind Marina Abramović's work 'Shoes for departure' (1991). These shoes are, however, heavy and big amethyst rocks with holes for feet cut out of them. They look a bit like traditional Dutch wooden shoes, heavy, big and inflexible wooden clogs. They are designed for hard work on the land, to be worn with woollen socks and straw inside; they could keep the feet dry, warm and safe from harm. Although Abramović's shoes seem to point at human use too, they are not made to move the body; on the contrary, their departure-part is meant for the mind. They are meant to transport the viewer into an altered state of consciousness. In the exhibition text for 'Dream Machines' (2000) curated by Susan Hiller, Abramović wrote the following instructions: "With naked feet enter the shoes. Eyes closed. Motionless. Depart. Duration: limitless. Material: amethyst." The work should create meaning in its interaction with the feelings and imaginations of a user when asked to re-enact the state of mind suggested by the artist.

\subsection{Non/Human Agency}

Bekirovic's and Abramović's works generate an opposite effect. In Bekirovic's 'Shoes' a non-human agency tries to 'grow' a new wearer in order to emancipate itself from the human; the shoes seem to want to take off on their own. Abramović's shoes fulfill the metaphorical function of mobilizing the human mind. Bekirovic's title 'Shoes' positions the shoes as protagonists. The word 'shoes,' being a noun without a verb, paralyzes the shoes while in fact they seemingly want to act. 'Shoes for Departure', however, hints at the shoes' functionality and their subordinate position towards a human protagonist. "Transitory objects for human use" reads the subtitle of Abramović's work (Hiller). Abramović has said about the altered state of consciousness:

[...] if you have all this energy, just sit in the chair and do nothing and see what happens. All this energy that would go outwards turns inwards, and 
something else happens (Stiles, Biesenbach \& lles, 21).

Abramovic wants to elevate the spirit of the spectators by letting them actively participate in the work. Bekirovic on the other hand wants to make works with things and not from or about them (personal communication, 27 April 2018). Bekirovic grew up with a physicist as father who had taught her that her hand resting on the table was in fact not so different from the table. Her experiments with psychedelics further enhanced her heightened sense of blending in with the things that surround her. Where Abramovic turns the energy inwards, Bekirovic turns it outwards. Bekirovic stresses, however, the importance of being able to indicate boundaries. "The funny thing is, that one can only be in this synesthetic state when one is truly capable of marking certain borders" (personal communication, 27 April 2018). This resonates with how the shoes have to simulate a life-like experience in order to be recognized by humans as an acting agent. First it has to blend in on a synesthetic level, only to reveal itself as other in its incongruity within this synesthesia. Maurer hypothesizes that a young infant confuses the input from different senses. When a child is born, 'it' floats in a sea of sameness, there is no difference between its own hand, the mother's face or the sheets on its bed. It does not know that it is part of something; it just is part of something. There is no sense of self because there are no limits to a self yet. Only when the infant is able to recognize itself as a self apart from other things, it can truly recognize other things as well.

\subsection{Audience}

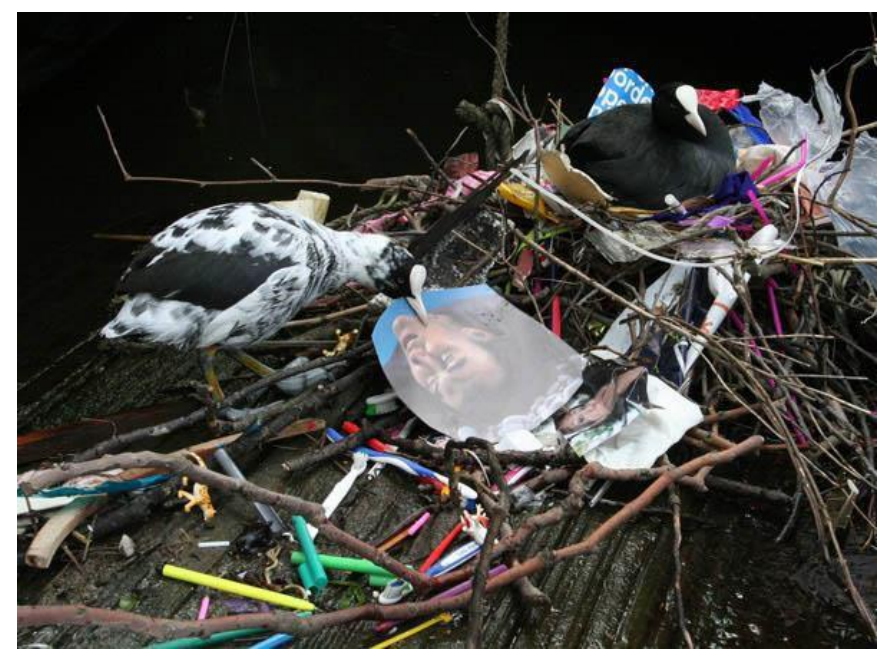

Figure 3: Semâ Bekirovic, Part of slide show and book 'Koet,' 2006-2007

Abramović's audiences are participating human subjects, while Semâ Bekirovic's audience is a more diffuse concept. There is a human audience of course who visits her exhibitions. However, whether that constitutes the whole audience is questionable.
Her video works are documentaries about specific events and experiences in which human and nonhuman entities participate. They in fact are performances that took place in front of a non/human eye, for example a surveillance camera, or Bekirovic's eye looking through a lens. In her work 'Koet', over a period of a few months, she fed a pair of common coots personal items which they incorporated in their nest. Interesting to her was the fact that the coots revaluated her objects. Once a toothbrush was of no use to her anymore, the coots would still find it very useful (personal communication, 27 April 2018). The coots are a highly involved and participatory audience reworking items, undoing them of function and refunctioning them again. Bekirovic is in turn their audience, participating in their value system, she learns what they would prefer and imagines what they might need next.

For Abramovic the audience became an increasingly important part of her work. In the show 'Generator' for the Sean Kelly Gallery in New York in 2014, she created what she has described as "full emptiness," a term derived from Tibetan teachings of oneness. The text on the website of the Sean Kelly Gallery reads:

Generator will be a unique environment for visitors to push the boundaries of their selfawareness and inner-consciousness, as they are confronted with nothing but themselves and the palpable energy in the room. In Generator, Abramović will focus on "nothingness." She will transform the main gallery into a space of sensory deprivation, an opportunity for forced introspection.

In order to create an uninterrupted state, visitors were required to leave their cellphones, watches, etcetera in a locker before entering the gallery. They were equipped with noise-cancelling headphones and blindfolds.

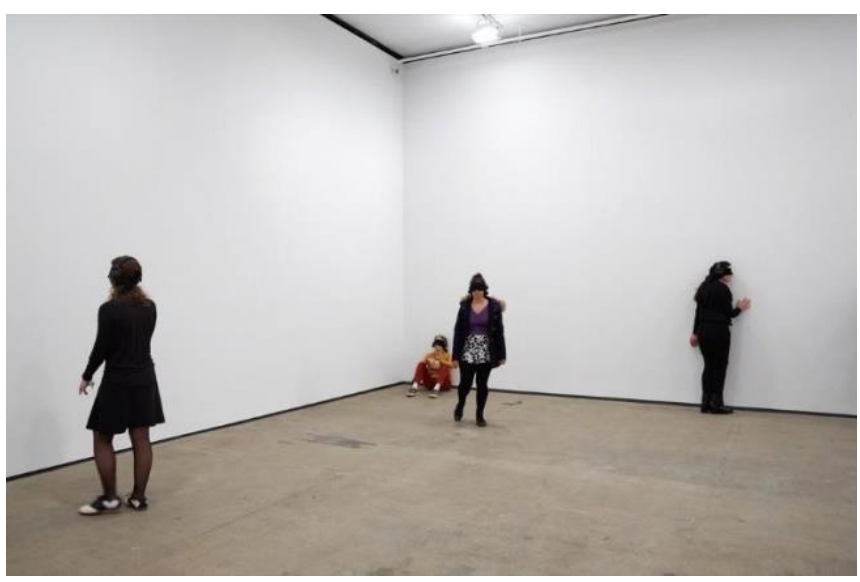

Figure 4: ‘Generator’ by Marina Abramović, Sean Kelly Gallery, New York, 2014 
In 'Generator' the visitors collapse inside of themselves. Abramović explicitly adheres to a thinking that linked art and science around the 1940 's with the explosion of the atomic bomb in 1945 renewing interest in Einstein's relativity theory. She does so by using the following quote by Alexander Dorner in her exhibition text: "The new type of art will be more like a power station, a producer of new energy" (website Sean Kelly Gallery). Dorner's statement can be contextualized for instance by Peter Blanc's declaration: "[t]oday nothing is left of matter ... all that is left is energy and the void. (152)" Blanc compared, for instance, Jackson Pollock's drip paintings with the traces of subatomic particles collisions recorded in cloudchamber photographs.

\subsection{Phase-Space}

Abramović's empty installation can also be linked to the 'Ganzfeld' experiment, conducted between the late 1920's to the mid-1960's. It was a scientific attempt begun with the work by German psychologist W. Metzger. In the 1960's, when experimental psychology lost interest in it, the experiment was picked up by artists such as James Turrell. The experiment consisted of creating a total field of vision. It involved making white light strike the retina uniformly through minute holes punctuated in Ping-Pong balls which were positioned over the eyes. According to Massumi, who has written extensively about this experiment, the most striking anomaly found was that vision would "blank out." He writes:

$$
\begin{aligned}
& \text { Under its purest empirical conditions, vision either } \\
& \text { fails to achieve itself or falls away from itself }- \text { and } \\
& \text { from the self. The empirical conditions of vision } \\
& \text { are not only not able to be held onto in } \\
& \text { experience, they prevent experience from holding } \\
& \text { onto itself }(2002,145) \text {. }
\end{aligned}
$$

One of the research subjects described that he saw "levels of nothingness" leading up to indeterminacy which was endorsed by all the other subjects in the experiment. There was nothing of definite size and nothing illuminated or shadowed, there was nothing that could be construed as an object. When Abramović speaks about confronting visitors with "nothing but themselves and the palpable energy in the room," I wonder whether it will lead up to what Massumi calls a vacuum? He describes the vacuum as:

[...] the random coming into and out of existence of all possible particles, excluding only stability. It is chaos. Pure vision, the simplest fullest empirical conditions of vision, is visual chaos (2002, 146).

He states that it will generate "the "phase-space" of being." While Abramović is interested in elevating visitors, I imagine them experiencing the loss of themselves.

This is quite different in Bekirovic' works that intentionally reach out of the self to become other. Central to her work is the sense of agency. According to Barad:

[...] agency cannot be designated as an attribute of 'subjects' or 'objects', it is 'doing'/'being' in its intra-activity (827).

Bekirovic shares Barad's idea that there are ever changing possibilities to act and that these possibilities entail a responsibility to intervene in the world's becoming. Barad calls this agential realism. There is a performativity in the formation of the subject that makes it all the more important to understand the nature of this production. It is through specific agential intra-actions that the boundaries and properties of the 'components' of phenomena become determinate and that particular embodied concepts become meaningful. Barad speaks of exteriority-within-phenomena which is somehow related to what Bekirovic describes as her experience of hallucinating while using psychedelics. In her hallucinations she experienced boundaries which could belong to her or to other things within the hallucination. Without these liminal aspects, again, a vacuum might be the result. These boundaries however are not static, they do not sit still, only through intra-actions they become visible.

\section{RELATIONAL VOODOO}

With the help of the writings of physicist Niels Bohr, Barad explains the role of "measuring agencies." There is a famous example of light passing through a two-slit diffraction grating exhibiting wave-like behaviour. When one intends to test the hypothesis that light exhibits particle like characteristics as well, one could, however, modify the diffraction apparatus to show this. Light can never be seen behaving like a wave or like a particle simultaneously or even measured with the same apparatus. With one apparatus it becomes a wave and with the other a particle. Apparatuses are themselves phenomena and measurement is nothing more or less than a causal intra-action. Barad shows that measurement is an act of one agency towards another. Measurement acts upon something. It is not an objective tool standing outside of the phenomenon, it is part of it and it includes the measuring agency as one of its components. Barad states therefore that objectivity implies being accountable to marks on bodies. To accept the fact that phenomena are made up of components intra-acting, means accepting that one cannot collapse inside oneself in some sort of vacuum but one is always entangled in an event with other agencies. 


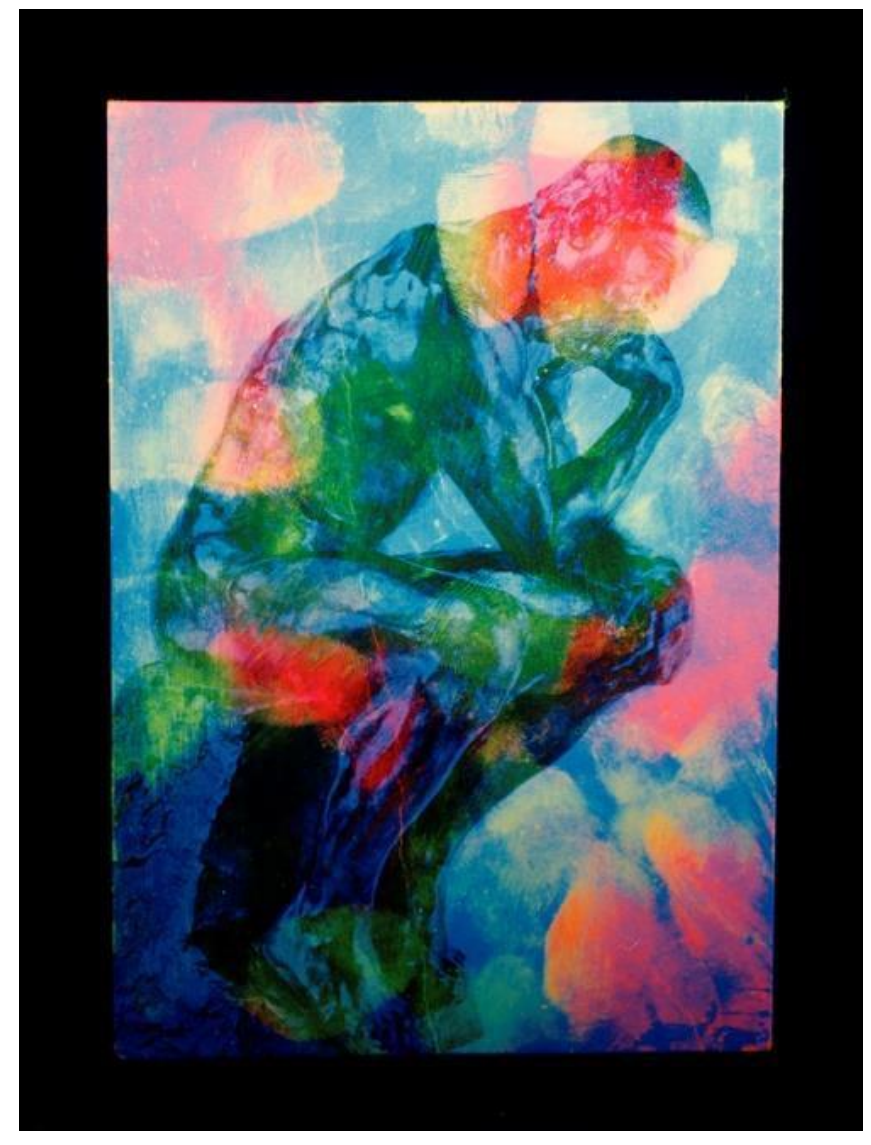

Figure 5: 'Relational Voodoo l' by Semâ Bekirovic, 2015.

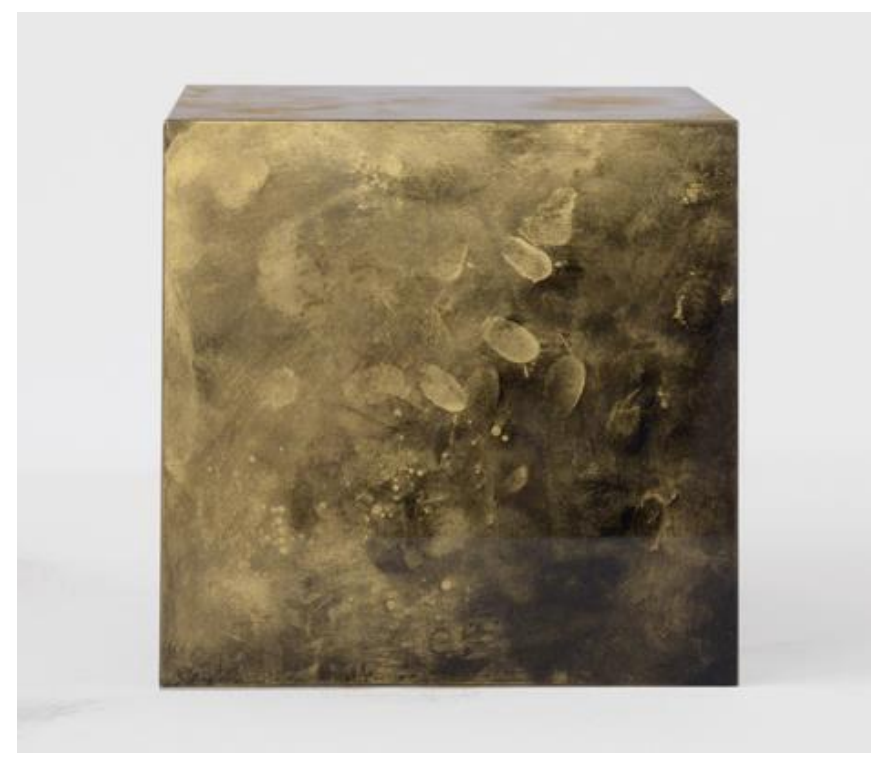

Figure 6: ‘Kubus 02’ by Semâ Bekirovic, 2017.

In her work 'Relational Voodoo I' (2015), Bekirovic has dusted flea-market-bought-objects with forensic powder and illuminated them with UV-lamps, revealing the objects' personal history by showing the smudges and fingerprints that form the objects' outer skin, which is usually invisible. Marks on bodies are brought to light relating to Barad's notion of accountability. Bekirovic found a life-size copy of
Rodin's thinker (which was depicted on a postcard she used in Relational Voodoo I) and staged it in an exhibition as 'Relation Voodoo II' (2016). In a dark room, let with UV-light, it sat there, exposing its marks. This work could also bear the title of one of her other works: 'Every atom belonging to me as good belongs to you' (2017) since it clearly shows how hands have overlapped in time, touched each other, even sharing atoms with one another. In her work 'Kubus 02' (2017) the fingerprint powder "special gold" was applied on a black acrylic cube that she had asked a factory to make for her. The people who worked there, were instructed not to wear gloves while working on it. This ensured that all traces of the making process (fingerprints, smudges, etc.) were retained and it revealed the object's hidden traces of being handled.

\subsection{Visual Substitutes for Non-Visible Ingredients.}

In 'The Radiance of Sensible Heat 02' (2016), the transference of body heat from hands to objects, brings them into focus as they light up with the heat.

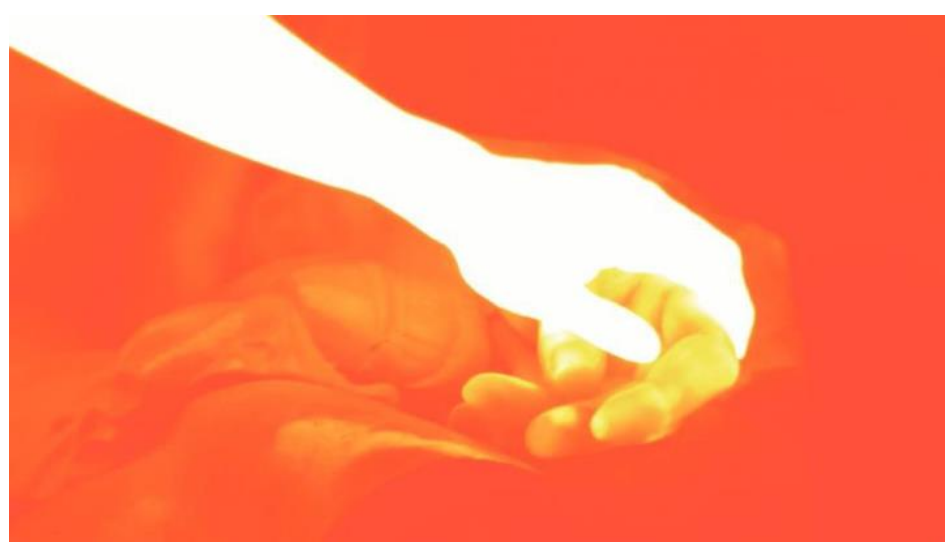

Figure 7: 'The Radiance of Sensible Heat' by Semâ Bekirovic, 2016.

A warm hand caresses a sculpture captured by a thermal camera. The sculpture radiates its presence. The objects are normally hidden from sight in the plaster sculpture depot of the Rijksakademie in Amsterdam. A statement by Langer might explain what is at stake in this work:

Everything that is given at all is given to vision; therefore we must have visual substitutes for the things that are normally known by touch, movement or inference. That is why a direct copy of what we see is not enough. The copy of things seen would need the same supplementation from non-visual sources that the original perception demanded. The visual substitutes for the nonvisible ingredients in space experience make the great difference between photographic rendering and creative rendering $[\ldots](73)$. 
The hands caressing the sculptures not only bring them to light but it brings them 'a-life.' It happens quite literally also since one of the characteristics of life is body-warmth as opposed to a cold dead body. Bekirovic shows in her work that viewing is not an act of a fixed objective eye. It is an event as phenomenon, entangling viewers as actants within its system.

\section{A YAWNING GAP}

To recapitulate the path from Abramovic to Bekirovic, Abramović taught the viewer to enter oneself and tap into some universal space of energy. Bekirovic subsequently introduced interacting agencies outside oneself. This path reflects Haraway's plea that:

\section{[...] we need to learn in our bodies, endowed with primate color and stereoscopic vision, how to attach the objective to our theoretical and political scanners in order to name where we are and are not, in dimensions of mental and physical space we hardly know how to name (9).}

We can conclude that in Haraway's "space we hardly know how to name," the human perspective is still dominant and, perhaps, obstinate. Langer's observations on the life-like experience in art fester on. What she calls "living-form" expresses lifefeeling, growth, movement, emotion, and everything that characterizes vital existence. She goes on to state that this concept is:

[...] a presentation of a highly articulated form wherein the beholder recognizes, without conscious comparison and judgement but rather by direct recognition, the forms of human feeling: emotions, moods, even sensations in their characteristic passage (82).

It might be the case that only by means of recognizing human aspects in something else, that we might become aware of this others' agency. There is a yawning gap between Abramović's collapse into what Massumi calls the empty 'spacephase' where nothing can be discerned at all, and Bekirovic's escalating 'outo' what Barad defines as intra-activities. In the first approach we lose ourselves all together; in the second there is the risk of only to be confronted with oneself as if in a mirror palace. Langer sobers us up by stating that:

The mental shift is as definite as that which we make from hearing a sound of tapping, squeaking, or buzzing to hearing speech, when suddenly in the midst of the little noises surrounding us we make out a single word (84).

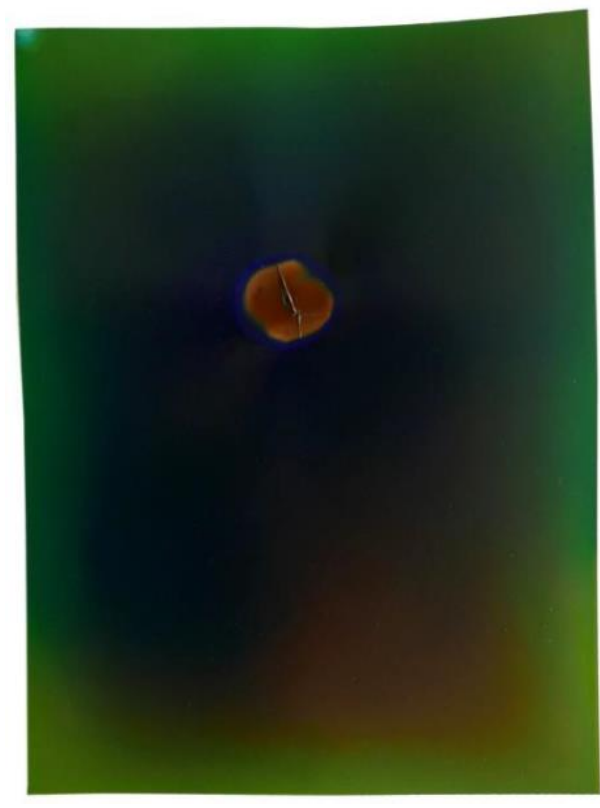

Figure 8: One of the series 'Combustions' (pyrography) by Semâ Bekirovic, 2014-2015.

However, to leave the door crack-open, the last word is given to Bekirovic's analog photography series 'Combustions'. In this series photographic paper is first 'exposed' by burning it; after that the papers are developed in the usual way. As result we see both the photographic representation and the physical remnant of the burning. Since it is the photographic paper that burns and creates the image, we could say that its partaker agency helped to expose itself.

\section{REFERENCES}

Barad, K. (2003) Posthumanist Performativity: Toward an Understanding of How Matter Comes to Matter. Signs: Journal of Women in Culture and Society, 28 (3), pp. 801-831.

Blanc, P. (1951) The artist and the atom. Magazine of art, 44, pp. 145-152.

Dorner, A. (1958) The Way Beyond 'Art', New York University Press, New York.

Haraway, D. (1988) Situated Knowledges: The Science Question in Feminism and the Privilege of Partial Perspective. Feminist Studies 14 (3), pp. 575-599.

Hiller, S. \& Fisher, J. (2000) Dream Machines, Hayward Gallery, London.

Langer, S. (1953) Feeling and Form A Theory of Art. Charles Scribner's sons, New York.

Massumi, B. (2002) Parables for the Virtual. Duke University Press, Durham.

---. (2007) The Thinking-Feeling of What Happens. Interact or Die, pp. 70-91. 
Maurer, D. (1993) Neonatal Synesthesia:

Implications for the Processing of Speech And Faces. Developmental Neurocognition: Speech and Face Processing in the First Year of Life, pp. 109124.

Stern, R., (2013) A Conversation with Semâ Bekirovic. http://www.lavalette.com/a-conversationwith-sema-bekirovic/ (Accessed 27 April 2018).

Stiles, K., Biesenbach, K. \& Iles, C. (2008) Marina Abramović, Phaidon, London.

Website Sean Kelly Gallery. http://www.skny.com/exhibitions/marinaAbramović4 (Accessed 15 May 2018).

I would like to thank professor Peter Sonderen of the ArtEZ professorship Theory in the Arts for commenting and reviewing my text and Semâ Bekirovic for sharing insights on her work-process with me. 